\title{
Traces of fatigue in an attention dual task
}

\author{
KAREL VERVAECK, MICHEL DEBOECK, JOHAN HUETING, and ERIC SOETENS \\ Vrije Universiteit Brussel, Brussels 1160, Belgium
}

\begin{abstract}
Effects of physical effort have been difficult to find in attention tasks for various reasons, such as the activating effect of the laboratory situation or the spare capacity in automated tasks. Instead, a double task, reflecting quantitatively the changes of information processing, is proposed. Thirty minutes after a paced circuit training, a visual-auditory task was presented for $\mathbf{4 0} \mathrm{min}$ : tachistoscopically presented dot patterns together with high and low tones. This was done at an easy pace, leaving it up to the subject to decide what to reproduce, as in normal circumstances. No effect was found in the total correct scores or in the auditory task. Deterioration was found only in the more difficult part of the visual task. The results can be explained in terms of Kahneman's variable-allocation capacity model. This method seems promising for separating effects on different stages of information processing.
\end{abstract}

Intuitively, it is felt that important changes should take place in information processing when people get tired. Nevertheless, during many decades, so-called attention tests of the Bourdon, Wiersma, Kraepelin, Zazzo, and so on, type give deceptive results. Reading tasks lasting hours (Carmichael \& Dearborn, 1947/1972) demonstrate no clear sign of deterioration. A new impetus came from Broadbent (1971) and some other investigators. The tasks were essentially better defined and of a paced nature, and they were, therefore, more comparable within and between subjects, which has led to a better insight into some important aspects of attention (for a review, see Broadbent, 1971). But surprisingly, in this new approach, the results obtained in the laboratory did not match the common observations that fatigued subjects are easily distracted or unable to concentrate for more than a short time. And even in the laboratory, the results were not consistent in terms of faults, variance, omitted responses, blocks, and so on (Sanders, 1967). More recently, Blitz, Janssen, and Sijbling (1973) and Näätänen (1973) asked the subjects to perform on different levels of physical load on a bicycle ergometer, while making them carry out, respectively, problem solving tasks and simple reaction time (RT) tasks. Both reported no changes as consequences of the load levels.

Three points are relevant in this situation. First, the experimental situation in the laboratory can motivate subjects in a formidable way, thus creating artificial levels of activation. Attempts were made to calibrate the reserves left in the subject by presenting high stimulus frequencies or low frequencies, reinforced by double tasks. This approach of provoking the breaking point of

The second author is supported as a research assistant by the Belgian National Fund for Scientific Research. Requests for reprints should be sent to Johan Hueting, Laboratorium voor Experimentele Psychologie, Waverse steenweg 1077, B1160 Brussels, Belgium. the subjects demonstrated that little room was left to differentiate between the starting states of the individual (e.g., fatigued vs. control). Second, it is well-known to every experimenter in this field that even the most simple-looking RT task shows prolonged effects of practice, learning, and habituation, as demonstrated in the RTs themselves and in correction times. To a great extent this may prevent the manifestations of the possible signs one is looking for. Third, in line with the point last mentioned, much room is often left for mind wandering during automated tasks for the well practiced subject. This leaves a great flexibility in allocating efforts to the demand characteristics of the task.

With the point last mentioned, we are coming into the line of Kahneman's (1973) reasoning, stressing the approach of indirect measuring of the load effects via the spare capacity when the tasks leave it up to the subject to allocate his effort to different aspects.

Bearing in mind these not well explained failures to trace the effects of severe physical effort in attention tasks, we opted for the following characteristics for our experimental design. First, we want to shape a nontypical laboratory situation for inducing effort and testing the effects. Second, fatigue will be induced by letting the subjects perform a physical paced task at a nearly maximum level. Third, an attention double task will be presented, so that both the selective and the intensive aspects of attention are taken into account. Finally, an attention task will be presented at an "easy," far below maximum, pace, leaving it up to the subject to decide what to reproduce. One of the two tasks has to be selected carefully, so that a change of the information processes can be reflected quantitatively in the performance.

\section{METHOD}

\section{Subjects}

Twenty male 1st-year physical education students aged between 18 and 21 years participated in the experiment. 


\section{Physical Task}

Circuit training consisted of 10 different exercises, such as working at the double bars, throwing a medicine ball, and so on. Each exercise took $40 \mathrm{sec}$, with $20 \mathrm{sec}$ rest after each exercise, during which the heart rate was measured. Three rounds of 10 exercises had to be completed, the total lasting $30 \mathrm{~min}$. The average heart rate during training was about 150 beats/min, with a standard deviation of 14 .

\section{Attention Double Task}

The double task consisted of an auditory and a visual component. The auditory task was a binary choice task, consisting of two tones $(500 \mathrm{~Hz}$ and $2,000 \mathrm{~Hz})$, each lasting $5 \mathrm{sec}$. The tones were recorded in a random sequence on a tape and played back at a loudness level of about $70 \mathrm{~dB}$. The visual component was a classical span-of-attention task, with black dots presented by means of a constant-illumination tachistoscope, consisting of two projectors with $500-\mathrm{W} 125-\mathrm{V}$ bulbs. The stimuli consisted of 81 slides, each containing 3-12 black dots on a white surface. Care was taken to spread the dots systematically over the surface. They were projected for $.10 \mathrm{sec}$ at an irregular pace of five to six per minute.

\section{Procedure}

The screen was placed at $5 \mathrm{~cm}$ distance, the image being a square of $50 \times 50 \mathrm{~cm}$, with black dots of $2.5-\mathrm{cm}$ diameter. The classroom was semidarkened, illuminated by the constant illumination of the tachistoscope. The subjects were seated at a distance of 3-5 $\mathrm{m}$ from the screen. They had to write down their responses on a special form in the sequence as all the stimuli (visual and auditory) appeared, according to the following code: a vertical line for a high tone and a horizontal line for a low tone. The visual stimuli were noted by the number of dots.

If the subjects did not know the answer, they had to write a zero. Every minute, subjects were instructed to restart on a new line by means of another taped message. The turning of the carousel of the tachistoscope served as a warning signal $1.1 \mathrm{sec}$ before the presentation of the visual stimulus. The attention double task lasted $40 \mathrm{~min}$ (i.e., 215 visual stimuli and 486 auditory stimuli). Subjects got accustomed to the task during a 1th training period.

A crossover design was used. The group was divided at random into two groups ( $\mathrm{A}$ and $\mathrm{B}$ ) of 10 subjects who participated in two sessions. In the first session, Group $A$ performed a circuit training for about $30 \mathrm{~min}$. After a 30 -min rest period, both groups (A and B) participated in the attention double task, lasting $40 \mathrm{~min}$. In the second session, 1 week later, $A$ and B groups were switched.

\section{RESULTS AND DISCUSSION}

The results for the second condition, with physical effort, were compared with the condition without physical effort. Table 1 contains the means of correct responses. The total scores show no effect of physical

Table 1

Mean Correct Responses on the Auditory and the Visual Task Without Physical Effort and With Physical Effort

\begin{tabular}{lcccc}
\hline \multirow{2}{*}{$\begin{array}{c}\text { Correct } \\
\text { Responses }\end{array}$} & $\begin{array}{c}\text { No Physical } \\
\text { Effort }\end{array}$ & $\begin{array}{c}\text { Physical } \\
\text { Effort }\end{array}$ & Wilcoxon Test* \\
\cline { 5 - 6 } Total & 593.70 & 594.80 & 20 & T \\
Auditory Task & 481.65 & 482.50 & 18 & 92.5 \\
Visual Task & 112.05 & 112.30 & 19 & 87.0 \\
\hline
\end{tabular}

*All results were nonsignificant.
Table 2

Error Responses and Zero Responses on the Visual Task Without Physical Effort and With Physical Effort

\begin{tabular}{lcccr}
\hline & $\begin{array}{c}\text { No Physical } \\
\text { Effort }\end{array}$ & $\begin{array}{c}\text { Physical } \\
\text { Effort }\end{array}$ & \multicolumn{2}{c}{ Wilcoxon Test } \\
\cline { 5 - 5 } Responses & 7.85 & 15.45 & 19 & $\mathrm{~N}$ \\
\hline Total Zero & 95.60 & 87.80 & 20 & -69.5 \\
Total Error & \multicolumn{4}{c}{ Stimuli With Six or Fewer Dots } \\
Error & 13.55 & 8.60 & 20 & -59.5 \\
Zero & 3.55 & 5.55 & 17 & 53.5 \\
& \multicolumn{5}{c}{ Stimuli With Seven or More Dots } \\
Error & 82.05 & 79.20 & 19 & -83.0 \\
Zero & 4.30 & 9.90 & 20 & 37.5 \\
\hline
\end{tabular}

Note-For total zero responses, $p<.02$; for zero responses to stimuli with seven or more dots, $p<.01$. All other results were nonsignificant.

effort. The auditory task is performed almost perfectly in both conditions. In the visual task, however, fewer errors are made in the task after physical effort, which is contradictory to what intuitively should be expected. The number of faulty visual responses can be differentiated into errors and zero responses. It is possible to differentiate even further on the basis of the number of dots. Woodworth and Schlosberg (1954) in their review of the classical span of attention research, noted a difference in the way of ascertaining the numbers up to 5-7 and higher. Recently, Lorinstein and Haber (1975) found a different processing time for counting up to six dots and more. This has been confirmed with the present apparatus and stimuli during numerous students' practical works. Slightly influenced by individual differences, the basic observation is that numbers smaller than or equal to six show substantially fewer faults than larger numbers. Therefore, we divided the errors and zero responses to visual stimuli into smaller than or equal to six and larger than six. The results are shown in Table 2. In this table, it can be seen that the difference in zero responses between the two conditions exists particularly in the number of dots greater than or equal to seven. Only in this condition, a significant difference is found. Figure 1 clearly illustrates this phenomenon. In short, subjects gave more zero responses to stimuli with larger numbers of dots after the physical effort condition than after the control condition.

The findings are in agreement with Kahneman's (1973) variable-allocation capacity model. In this model, the completion of a mental activity requires two types of input to the hypothetical corresponding cognitive structure: first, an information input specific to that structure, and second, a nonspecific input of attention or effort resulting from a limited total amount of attention that can be deployed. Therefore, an activity that has received an information input can still fail because the supply of attention does not meet the demands. 


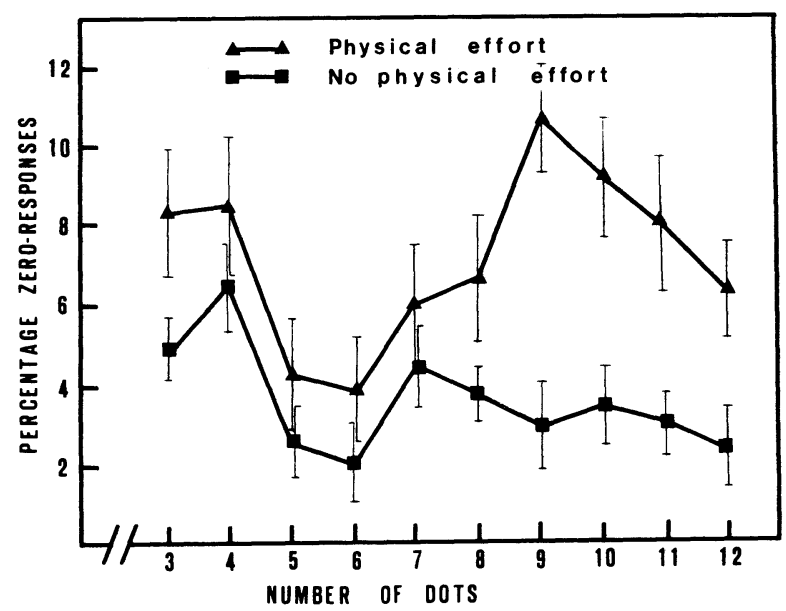

Figure 1. Mean percentage of zero responses in function of the number of dots. Vertical bars indicate \pm 1 standard error of mean.

It seems reasonable to suppose that there is less capacity available after physical effort. In this case, according to Kahneman (1973), those activities would first fail that are "difficult" or "effort demanding," which in terms of his model is especially related to time pressure. This is exactly what was found. Time pressure necessarily arises in any task that imposes a significant load on short-term memory. Lorinstein and Haber (1975) suggested that when there are many dots to count, it may be that short-term memory is needed to keep track of the accumulating count and to label which of the dots have already been counted. Since shortterm memory is expected to overload around six items, it is for the numbers greater than or equal to seven that the time pressure will be felt, and consequently, it is there that a failure in the supply of attention will first be noticeable.

Why, then, are there not more mistakes for the larger number of dots after physical effort? Posner and Keele (Note 1) noted that the demands for effort increase as one approaches the response end of the information processing system. Kahneman (1973) demonstrates that it is plausible that the selection of a response is highly demanding in attention effort. This agrees with our findings that it is the making of a decision that is influenced by physical effort as reflected in the zero responses, rather than the precision as reflected in errors and coefficients of accuracy. The making of a decision about a larger number of dots will, as a result, be extra demanding of attention. Therefore, subjects will evade a decision by giving more zero responses to these larger numbers when the supply of attention is limited after physical effort. This also means that there is less room for making errors, which explains the seeming contradiction that the number of errors decreases slightly, although not significantly, after physical effort.
The significant difference in zero responses depending on the number of dots (see Figure 1) obviously means that the subject must have formed an idea about the quantity of the dots. Based on Sperling (1960), we can accept that all the dots are represented in the visual information storage. The present results suggest that, in the case of a random visual pattern of dots, enough information is passed on swiftly that the subject obtains a quick idea of the complexity of the visual image (i.e., of the effort required to process it). This information, combined with an evaluation of the supply of attention, should enable the subject to make a decision about continuing or stopping the process. If we assume this idea, a parallel processing must take place, having at least one fast processing line (due to multiple quantitatively different encoding), which results in rough categories, such as a few, a lot, and so on, with connections with the effort involved. Such a feedback mechanism, as described above, can be thought to work along the the same lines as perception at meaningful levels before we are aware of prior analyses, as recent evidence suggests (Craik \& Lockhart, 1972). It could be argued that guessing in rough quantities of a number of objects is a familiar, well established activity, and that, therefore, this parallel subprocess is executed more rapidly into a greater degree of organization. This may be compared with the faster processing of meaningful stimuli (e.g., sentences) (Craik \& Lockhart, 1972). In fact, this fast analysis in global categories might be considered as an attempt to give a "meaning" to a random dot pattern. The subsequent finer analysis, the exact counting of dots, is then a slower process that can be interrupted.

The exact mechanisms involved in the processing of random dots have to be proved in more vigorously controlled experiments, in which, for instance, the processing time is controlled by using a visual backward-masking technique. However, one must be careful with individually tested subjects, as they might react to the demand characteristics of the laboratory situation and as a result make a greater effort, which might change their decision criteria.

Nevertheless, the dual task method has done more than providing us with a simple measure of the influence of physical effort, which was our original intention. It has shown the possibility that different processing might be separately influenced by what we have called fatigue and that the influence on the decision can be different for larger and smaller numbers. Hopefully, the method will continue to be useful in the further search for the exact processes involved.

\section{REFERENCE NOTE}

1. Posner, M. 1., \& Keele, S. W. Time and space as measures of mental operations. Invited address (Division 3) presented at the annual meeting of the American Psychological Association, Miami Beach, Florida, September 1970. 


\section{REFERENCES}

Blitz, P. S., Janssen, C. G. C., \& Sijbling, G. [The influence of physical exercise and amphetamine on cognitive functions] (in Dutch). Geneeskunde en Sport, 1973, 4, 33-36.

Brondbent, D. S. Decision and stress. New York: Academic Press, 1971.

Carmichael, L., \& Dearborn, W. F. Reading and visual fatigue. Westport, Conn: Greenwood Press, 1972. (Originally published, 1947.)

Craik, F. I., \& Lockhart, R. S. Levels of processing: A framework for memory research. Journal of Verbal Learning and Verbal Behavior, 1972, 11, 671-684.

Kahneman, D. Attention and effort. Englewood Cliffs, N.J: Prentice-Hall, 1973.

Lorinstein, B., \& Haber, N. Perceived numerosity: An infor- mation processing analysis. Canadian Journal of Psychology, 1975, 29, 224-236.

NÄÄTÄNEN, R. The inverted-U relationship between activation and performance: A critical review. In S. Kornblum (Ed.), Attention and performance IV. New York: Academic Press, 1973.

Sanders, A. F. [The psychology of information processing] (in Dutch). Arnhem, The Netherlands: Van Loghum Slaterus, 1967.

Sperling, G. The information available in brief visual presentations. Psychological Monographs, 1960, 74, 1-29.

Woodworth, R. S., \& Schlosberg, H. Experimental psychology. New York: Holt, 1954.

(Received for publication December 5, 1981.) 